\title{
Molecular and neural bases underlying roles of BDNF in the control of body weight
}

\author{
Filip Vanevski and Baoji Xu*
}

Department of Pharmacology and Physiology, Georgetown University Medical Center, Washington, DC, USA

\section{Edited by:}

Kevin W. Williams, The University of Texas Southwestern Medical

Center, USA

Reviewed by:

Jiehuan Huang, Pennsylvania

State University, USA

Maribel Rios, Tufts University

School of Medicine, USA

James R. Munoz, Nova

Southeastern University, USA

${ }^{*}$ Correspondence:

Baoji Xu, Department of

Pharmacology and Physiology,

Georgetown University Medical

Center, 3900 Reservoir Road NW,

Washington, DC 20057, USA.

e-mail: bx3@georgetown.edu
Brain-derived neurotrophic factor (BDNF) is a potent regulator of neuronal development and synaptic plasticity that is fundamental to neural circuit formation and cognition. It is also involved in the control of appetite and body weight, with mutations in the genes for BDNF and its receptor, TrkB, resulting in remarkable hyperphagia and severe obesity in humans and mice. Recent studies have made significant progress in elucidating the source, action sites, and regulatory pathways of BDNF with regard to its role in the control of energy homeostasis, and have shed light on the relationships between BDNF and other molecules involved in the control of body weight. Here we provide a comprehensive review of evidence from pharmacological, genetic, and mechanistic studies, linking BDNF to the control of body weight. This review also aims to organize the main findings on this subject into a more refined framework and to discuss the future research directions necessary to advance the field.

Keywords: brain-derived neurotrophic factor, TrkB, obesity, energy expenditure, ventromedial hypothalamus, paraventricular hypothalamus, dorsal vagal complex

\section{INTRODUCTION}

Brain-derived neurotrophic factor (BDNF) is a member of the neurotrophin family of secreted signaling molecules that includes nerve growth factor (NGF), neurotrophin-3 (NT3), and neurotrophin-4/5 (NT4/5). Signal transduction can occur through the binding of two distinct classes of receptor proteins: the tropomyosin receptor kinase (Trk) family of receptor tyrosine kinases, which includes TrkA, TrkB, and TrkC, or the p75 neurotrophin receptor $\left(\mathrm{p} 75^{\mathrm{NTR}}\right)$. The Trk receptors have different neurotrophins as their preferred ligands, with NGF binding to TrkA, BDNF and NT4/5 binding to TrkB and NT3 binding to TrkC, while all of the neurotrophins can bind to $75^{\text {NTR }}$ (Barbacid, 1994; Bibel and Barde, 2000; Reichardt, 2006). Neurotrophins are expressed both during development and throughout adulthood (Hofer et al., 1990; Yan et al., 1997b). They play crucial roles both in the proper wiring of neural circuits and in the modulation of connections in the mature nervous system by influencing neuronal survival and differentiation as well as synapse formation and plasticity (Chao, 2003; Waterhouse and $\mathrm{Xu}, 2009)$.

Perturbation of normal BDNF levels has been associated with many disease states, including Alzheimer's disease, Parkinson's disease, Huntington's disease, schizophrenia, and depression (Teixeira et al., 2010; Diniz and Teixeira, 2011; Satomura et al., 2011). Recent genetic data has also linked deficiencies in TrkB signaling to obesity (Rios et al., 2001; Xu et al., 2003; Yeo et al., 2004).

A key molecule involved in the control of body weight is leptin, which is the protein product of the $o b$ gene and is produced and secreted from adipose tissue, and serves as an indicator of fat mass (Zhang et al., 1994; Elmquist et al., 1998). Its expression and secretion was found to be increased after either food intake or insulin injection, indicating that in addition to serving as a measure of adiposity, leptin levels can be modulated by nutritional status, probably through changes in insulin release regulated by blood glucose levels (Saladin et al., 1995; Barr et al., 1997; Boden et al., 1997). Treatment with leptin can lead to reduced fat storage through reduction in food intake as well as by increasing energy expenditure (Hamann and Matthaei, 1996; Stehling et al., 1996). In addition to leptin, many other factors have been shown to regulate energy balance, including insulin produced in the pancreas (Woods et al., 1979), glucagon-like-polypeptide-1 produced in the ileum (Tang-Christensen et al., 1996; Turton et al., 1996), peptide tyrosine tyrosine produced in the terminal ileum and colon (Batterham et al., 2002), cholecystokinin (CCK) produced in the duodenum (Dockray, 2012), ghrelin produced in the stomach (Kojima et al., 1999; Nakazato et al., 2001), and various metabolites such as glucose, fatty acids, and amino acids (Loftus et al., 2000; Cota et al., 2006; He et al., 2006; Pocai et al., 2006).

These peripheral factors reach the brain via the circulatory system and are integrated in several brain regions, including the arcuate nucleus (ARC), dorsomedial hypothalamus (DMH), ventromedial hypothalamus $(\mathrm{VMH})$, paraventricular hypothalamus (PVH), and brainstem (Flier, 2004; Morton et al., 2006). The ARC is a hypothalamic nucleus with a well-demonstrated role in responding to peripheral signals of nutritional status, such as leptin, to regulate energy balance (Coppari et al., 2005). There are two distinct populations of neurons in the ARC involved in mediating this response: one that co-expresses proopiomelanocortin (POMC) and cocaine- and amphetamine-regulated transcript (CART), while the other co-expresses agouti-related protein (AgRP) and neuropeptide Y (NPY) (Parker and Bloom, 2012). One metabolite of POMC, alpha melanocyte-stimulating 
hormone $(\alpha-\mathrm{MSH})$, is an agonist of the melanocortin 4 receptor (MC4R). Conversely, AgRP is an inverse agonist of the MC4R (Ollmann et al., 1997). Furthermore, NPY can activate its receptors on POMC neurons in the ARC to induce hyperpolarization and decrease excitability (Cowley et al., 2001). Both populations express the leptin receptor, with signaling in POMC/CART neurons leading to increased secretion of $\alpha-\mathrm{MSH}$ and activation of anorexigenic pathways, while signaling in AgRP/NPY neurons results in decreased secretion of AgRP and NPY and relief of inhibition of these pathways (Ellacott and Cone, 2006; Williams et al., 2011). POMC neurons in the ARC receive strong excitatory input from the medial $\mathrm{VMH}$, which is decreased during fasting. NPY neurons in the ARC only receive weak inhibitory input from within the ARC itself (Sternson et al., 2005).

\section{THE Bdnf GENE AND ITS EXPRESSION}

The mouse and rat $B d n f$ genes have nine exons, the first eight of which contain $5^{\prime}$ untranslated regions ( $5^{\prime}$ UTRs), with exon IX containing the entire coding sequence as well as the $3^{\prime}$ untranslated region (3' UTR) (Timmusk et al., 1993; Aid et al., 2007). Transcription can be initiated at any of the eight untranslated exons, which are spliced to the common coding exon IX, generating mRNA species with different $5^{\prime}$ UTRs that code for the same protein. The number of potential transcripts is further increased by polyadenylation at either of two sites, one 350 bases downstream of the stop codon and the other at $2.85 \mathrm{~kb}$ downstream. Although the various transcripts encode the same protein, they are expressed differentially throughout development, have distinct spatial expression patterns, and respond uniquely to stimulation. Synthesis of some of these transcripts is regulated by the activity of the cyclic AMP responsive element binding protein (CREB) and methyl CpG-binding protein 2 (Tao et al., 1998; Chen et al., 2003). Recent studies investigating the relative importance of $B d n f$ mRNA sequences in directing mRNA trafficking have led to conflicting reports of which regions are involved, with work in our laboratory demonstrating a critical role for the long $B d n f 3^{\prime}$ UTR in directing dendritic trafficking (An et al., 2008), while another lab has shown the importance of coding and 5' UTR sequences (Chiaruttini et al., 2009; Baj et al., 2011). The various temporal, spatial and activity-dependent patterns of transcription for the different $B d n f$ mRNA species allows for highly specific and fine-tuned regulation of BDNF synthesis, which can be further refined by post-transcriptional regulatory mechanisms acting on RNA transcript stability and translational activation.

$B d n f$ mRNA has been detected in many brain regions, including the cortex, hippocampus, amygdala, $\mathrm{DMH}, \mathrm{PVH}, \mathrm{VMH}$, lateral hypothalamus (LH), ventral tegmental area (VTA), substantia nigra and nucleus of the solitary tract (NTS) (Conner et al., 1997; Xu et al., 2003). BDNF immunoreactive fibers, indicating possible sites of BDNF/TrkB signaling, were found in the cortex, hippocampus, nucleus accumbens (NAc), amygdala, ARC, DMH, LH, PVH, VMH, VTA, substantia nigra, dorsal raphe nucleus, and NTS (Conner et al., 1997; Katoh-Semba et al., 1997; Yan et al., 1997b). TrkB in the adult rat brain has been localized to the olfactory system, cortex, hippocampus, most nuclei of the hypothalamus, striatum, amygdala, septal nuclei, substantia nigra, cerebellar Purkinje cells, brainstem and spinal motor neurons, and brainstem sensory nuclei (Masana et al., 1993; Yan et al., 1997a; Kernie et al., 2000; Xu et al., 2003). Interestingly, not all areas that express $\operatorname{TrkB}$ are also sites of BDNF synthesis, though they may contain BDNF-positive fibers, a pattern seen in the striatum and ARC (Altar et al., 1997; Xu et al., 2003; Baydyuk et al., 2011b), indicating these areas as sites of anterograde or retrograde BDNF action, with BDNF originating from distal brain regions. In the areas that express both BDNF and $\operatorname{TrkB}$, autocrine or paracrine signaling is also possible, with TrkB activation occurring from binding of BDNF released from the same or neighboring cells.

\section{SECRETION AND SIGNALING OF BDNF}

BDNF is initially synthesized as a pre-pro-neurotrophin, containing a signal peptide directing sequestration of the nascent protein to the endoplasmic reticulum (ER), after which the signal peptide is cleaved, leaving proBDNF (Halban and Irminger, 1994). ProBDNF then traffics through the Golgi apparatus where it can be sorted into two different types of secretory granules, small vesicles that fuse to the plasma membrane and release their contents constitutively, or larger vesicles whose fusion to the plasma membrane is regulated and depends on $\mathrm{Ca}^{2+}$ levels (Lessmann et al., 2003). Intracellular cleavage of proBDNF to generate mature BDNF (mBDNF) was observed in hippocampal neurons (Mowla et al., 1999), and for a time it was believed that only secreted mBDNF was biologically active. Recent work has demonstrated that tissue plasminogen activator (tPA), a secretory protein implicated in the late phase of long-term potentiation (L-LTP), can lead to cleavage of secreted proBDNF to mBDNF by activation of plasmin, an extracellular protease (Pang et al., 2004; Yang et al., 2009). Furthermore, secretion of proBDNF is biologically relevant, as its binding to $\mathrm{p} 75^{\mathrm{NTR}}$ can lead to cell death and long-term depression (Teng et al., 2005; Woo et al., 2005).

BDNF functions as a homodimer that can bind to and dimerize TrkB receptors, leading to their transphosphorylation on tyrosine residues located in their intracellular domains (Patapoutian and Reichardt, 2001). This event triggers three different signaling cascades through activation of mitogen-activated protein kinase (MAPK), phosphatidylinositol 3-kinase (PI3K) and phospholipase C-gamma (PLC $\gamma$ ). The MAPK pathway regulates neuronal differentiation and maturation, while the PI3K pathway is essential for neuronal survival (Reichardt, 2006). In addition, signaling through the MAPK pathway leads to activation of CREB and upregulation of its target genes, as well as phosphorylation of eukaryotic initiation factor $4 \mathrm{E}$ (eIF4E), 4E-binding protein 1 (4E-BP1) and ribosomal protein S6, playing an important role in the regulation of protein synthesis-dependent synaptic plasticity. The PI3K pathway also is an important regulator of synaptic protein synthesis and trafficking through the activation of Akt and the mammalian target of rapamycin (mTOR), which can phosphorylate 4E-BP1 to enhance translation (Bramham and Wells, 2007). Activation of the PLC $\gamma$ pathway leads to production of diacylglycerol (DAG), which can activate PKC, and inositol 1,4,5-triphosphate (IP3), which leads to the release of intracellular $\mathrm{Ca}^{2+}$ stores, resulting in enhancement of synaptic plasticity (Reichardt, 2006). 


\section{EVIDENCE FOR A CRITICAL ROLE OF BDNF IN ENERGY HOMEOSTASIS}

BDNF was first found to reduce body weight of adult rats in a study that was designed to examine the effect of chronic intracerebroventricular (icv) infusion of neurotrophins on presynaptic cholinergic function (Lapchak and Hefti, 1992). A subsequent study found that chronic injection of BDNF to the lateral ventricle of rats resulted in decreased food intake, leading to loss of body weight (Pelleymounter et al., 1995). A critical role for endogenous BDNF in the regulation of feeding behavior was demonstrated in mice with reduced BDNF levels, such as heterozygous BDNF $\left(B d n f^{+/-}\right)$mice, which had increased risk of obesity resulting from increased food intake, concomitant with elevated serum leptin and insulin levels (Lyons et al., 1999; Kernie et al., 2000). This genetic finding was confirmed and extended by the severe obesity phenotypes observed in mice expressing the TrkB receptor at $\sim 25 \%$ of normal levels (Xu et al., 2003) and in mice where the $B d n f$ gene is deleted in neurons expressing $\mathrm{Ca}^{2+} /$ calmodulin-dependent protein kinase II alpha (CaMKII $\alpha$ ) (Rios et al., 2001). Since CaMKII $\alpha$ is a brain-specific protein (Lin et al., 1987), this observation demonstrates that BDNF acts on neurons of the central nervous system to affect energy balance.

Deficiencies in BDNF signaling are also associated with obesity in humans. A de novo missense mutation in a key tyrosine residue of the TrkB kinase domain or loss of a functional $B d n f$ allele has been found to be associated with hyperphagia, severe obesity, and impaired cognitive function in children (Yeo et al., 2004; Gray et al., 2006). A subgroup of patients with the Wilms' tumor, aniridia, genitourinary anomalies, and mental retardation (WAGR) syndrome display hyperphagia and obesity (Fischbach et al., 2005). The WAGR syndrome results from heterozygous, variably sized, contiguous deletions on chromosome 11, which extend into the Bdnf gene in some cases. Careful mapping of the deletion regions in 33 patients with the WAGR syndrome has identified haploinsufficiency of BDNF as the cause of the accompanied obesity disorder (Han et al., 2008). Furthermore, large-scale genome-wide association studies link a common single nucleotide polymorphism in the $B d n f$ gene, rs6265, to human obesity (Hotta et al., 2009; Thorleifsson et al., 2009), and rs6265 has been shown to be associated with human eating disorders (Ribases et al., 2004; Gratacos et al., 2007). This polymorphism changes the Val residue at position 66 of pre-pro-BDNF to a Met residue and impairs activity-dependent BDNF secretion through the regulated secretory pathway (Egan et al., 2003). Additional evidence of a role for BDNF in obesity comes from a knock-in mouse strain, which contains the Val66Met mutation and exhibits increased body weight (Chen et al., 2006).

\section{BDNF AS AN ANOREXIGENIC FACTOR}

BDNF plays crucial roles in the development and maintenance of neural circuits (Xu et al., 2000b; Huang and Reichardt, 2001; Baydyuk et al., 2011a). Thus, obesity syndrome induced by BDNF insufficiency could result from either diminished anorexigenic activity of BDNF or structural defects in neural circuits that are important for the control of energy homeostasis. The severe obesity phenotype in a mouse mutant where the $B d n f$ gene is deleted in many brain regions using a Cre transgene under the control of the CaMKII $\alpha$ promoter (Rios et al., 2001) has been widely cited as evidence for BDNF as an anorexigenic factor because the transgene starts to express Cre recombinase in the hippocampus during the third postnatal week, after many developmental events in the brain have already been completed (Tsien et al., 1996; Xu et al., 2000a). However, CaMKII $\alpha$ is expressed in the hypothalamus as early as the first postnatal week (An and $\mathrm{Xu}$, unpublished data), when many hypothalamic neurons are still sending their axons to targets (Bouret et al., 2004), suggesting that the development of hypothalamic neural circuits could be altered in this conditional Bdnf knockout. Indeed, one study showed that the projection of POMC-expressing neurons in the ARC to the DMH was impaired in one $B d n f$ mutant strain (Liao et al., 2012). More supportive evidence for BDNF as an anorexigenic factor comes from the observation that selective deletion of the $B d n f$ gene in the $\mathrm{VMH}$ and $\mathrm{DMH}$ of adult mice using Cre-expressing virus still induced hyperphagia and increased weight gain (Unger et al., 2007), although there is still the possibility that the Bdnf deletion leads to degeneration of an anorexigenic neural circuit.

If BDNF is acting as a mediator of signals regulating energy balance, its expression levels should change to reflect nutritional status. Two-day food deprivation was found to drastically reduce levels of $B d n f$ mRNA in the mouse VMH, without affecting $B d n f$ gene expression in the cerebral cortex (Xu et al., 2003). This observation not only demonstrates that BDNF is a bona fide anorexigenic factor, but also indicates the importance of $\mathrm{VMH}$ BDNF in the control of energy homeostasis. Furthermore, food deprivation was also found to reduce BDNF protein levels in the dorsal vagal complex (DVC) (Bariohay et al., 2005). Whether food deprivation alters $B d n f$ gene expression in the $\mathrm{DMH}, \mathrm{LH}$, and PVH remains to be determined. Melanocortin and glucose are likely key mediators linking energy status to $B d n f$ gene expression in the $\mathrm{VMH}$, as administration of either a melanocortin analog or glucose into fasted mice increased levels of $B d n f$ mRNA in the VMH (Xu et al., 2003; Unger et al., 2007). The Bdnf gene is expressed from multiple promoters in the VMH (Tran et al., 2006; Unger et al., 2007), and glucose regulates Bdnf gene expression in the VMH through the exon I promoter (Unger et al., 2007). One study reported that systemic leptin administration increased levels of $B d n f$ mRNA and BDNF protein in the VMH (Komori et al., 2006). Since BDNF neurons in the VMH do not express the leptin receptor (Liao et al., 2012), leptin may indirectly regulate $B d n f$ gene expression in the $\mathrm{VMH}$.

Collectively, these studies show that BDNF levels in some brain regions change in response to nutritional status and that postnatal ablation of BDNF expression leads to hyperphagia and obesity. These biochemical and genetic findings, along with the pharmacological observation that icv infusion of BDNF reduces food intake and body weight (Lapchak and Hefti, 1992; Pelleymounter et al., 1995), strongly indicate that BDNF acutely and actively regulates energy homeostasis. Given the crucial role of BDNF in neuronal development, it is conceivable that developmental defects in neural circuits also contribute to the massive obesity observed in mice with impaired BDNF activity. Interestingly, central infusion of BDNF was found to reverse hyperphagia and excessive weight gain in $B d n f^{+/-}$mice (Kernie et al., 2000). This result suggests that developmental defects in neural circuits 
relevant to feeding are not permanent in $B d n f$ or $\operatorname{Trk} B$ mutants and could be overcome in later life by increasing BDNF activity.

\section{ROLES OF BDNF IN THE REGULATION OF ENERGY EXPENDITURE}

A decrease in energy expenditure can lead to obesity, and one of key forms of energy expenditure is thermogenesis. In mouse and rat, the interscapular brown adipose tissue (IBAT) is the major site of thermogenesis. Sympathetic inputs from the stellate ganglion increase the expression of uncoupling protein 1 (UCP1) in IBAT, which allows the energy generated from $\beta$ oxidation of fatty acids to dissipate as heat in response to physiological stimuli such as cold exposure and overeating (Cannon and Nedergaard, 2004; Clapham, 2012). Some neurons in several hypothalamic areas, including $\mathrm{DMH}, \mathrm{LH}, \mathrm{PVH}$, and retrochiasmatic area, are poly-synaptically connected to IBAT, as revealed by pseudorabies virus retrograde tracing (Oldfield et al., 2002; Cano et al., 2003).

Both peripheral and icv administration of BDNF were found to increase turnover of norepinephrine and UCP1 gene expression in IBAT and to restore thermogenesis in food-deprived $d b / d b$ mice (Nonomura et al., 2001; Tsuchida et al., 2001). Direct injection of BDNF to the $\mathrm{PVH}$ and VMH in rats resulted in an increase in energy expenditure and a decrease in weight gain (Wang et al., 2007b, 2010). However, BDNF action in these two sites is not the same, as BDNF injection to the PVH was found to increase the expression of UCP1 in IBAT without affecting spontaneous physical activity (Wang et al., 2007b), whereas BDNF injection to the VMH increased spontaneous physical activity without altering UCP1 expression in IBAT (Wang et al., 2010). These pharmacological studies suggest that enhancing TrkB signaling in the $\mathrm{PVH}$ and VMH increases energy expenditure by either directly or indirectly modulating hypothalamic neurons that are connected to IBAT and the motor system, respectively. Interestingly, it was found that environmental enrichment increased thermogenesis by inducing the appearance of cells with prototypical brown fat morphology and high UCP1 levels in white fat tissue, and that BDNF mediated this effect of environmental enrichment (Cao et al., 2011). This observation suggests that endogenous BDNF also regulates energy expenditure, although it remains unknown if environmental enrichment affects thermogenesis in IBAT as well.

Genetic data collected from $B d n f$ mouse mutants has not painted a clear picture regarding the role of BDNF in energy expenditure. Pair feeding was found to correct excessive weight gain in Bdnf heterozygous mice (Coppola and Tessarollo, 2004), mice where the $B d n f$ gene was selectively deleted in the DMH and $\mathrm{VMH}$ (Unger et al., 2007), and mice lacking the long isoform of Bdnf mRNA (Liao et al., 2012). These studies indicate that the total energy expenditure in these mutants remains unchanged. This evidence shows a dominant role of hyperphagia in the development of obesity when BDNF signaling is impaired; however, it is not sufficient to rule out a role for BDNF in the regulation of energy expenditure. Bdnf heterozygous mice showed elevated locomotor activity (Kernie et al., 2000), which may compensate for reduced thermogenesis and/or reduced resting metabolic rate. It is possible that BDNF derived from the short isoform of $B d n f$
mRNA in a brain region other than the DMH and VMH may regulate thermogenesis and resting metabolism.

\section{PRODUCTION SITES OF THE BDNF PROTEIN CRUCIAL FOR ENERGY HOMEOSTASIS}

The VMH is likely a site for the synthesis of BDNF protein that is critical for energy homeostasis. The Bdnf gene is expressed in many neurons in the ventrolateral and dorsomedial parts of the $\mathrm{VMH}$, and its mRNA levels in this area are among the highest in the brain (Xu et al., 2003). Food deprivation was found to selectively and drastically reduce levels of $B d n f$ mRNA in the VMH (Xu et al., 2003), and administration of melanocortin agonists or glucose was able to partially reverse this reduction in Bdnf gene expression (Xu et al., 2003; Unger et al., 2007). This observation suggests that hunger suppresses $B d n f$ gene expression in the $\mathrm{VMH}$, whereas feeding, which is accompanied by an increase in melanocortin signaling and glucose levels in the brain, does the opposite. This inference would predict that deletion of the $B d n f$ gene in the VMH should lead to hyperphagia and obesity. Deletion of the Bdnf gene in the VMH and DMH of adult mice with adeno-associated virus (AAV) expressing Cre recombinase indeed caused modest hyperphagia and obesity (Unger et al., 2007). However, this result does not completely address the role of VMH BDNF in the control of energy homeostasis, because the obesity phenotype in this mutant was very subtle in comparison to mutant mice where the $B d n f$ gene was deleted in many brain regions or where TrkB was systemically down-regulated (Rios et al., 2001; Xu et al., 2003). The subtlety of the obesity phenotype is likely due to incomplete AAV-mediated Bdnf deletion in the VMH. It may also result from the late onset of the $B d n f$ deletion, which would remove the impact of BDNF deficiency on neuronal development. When a Cre transgene driven by the promoter for steroidogenic factor 1 (SF1-Cre) was used to delete the Bdnf gene in SF1-expressing VMH neurons, the resulting mutant mice did not display any body weight phenotype (Dhillon et al., 2006). Given that SF1 and BDNF are only partially co-expressed in the VMH (Tran et al., 2003), this is not a surprising result. Development of additional VMH-specific Cre transgenic mice will greatly facilitate elucidation of the role of VMH BDNF in the control of feeding behavior and body weight.

Food deprivation also decreased levels of BDNF protein in the rat DVC, whereas refeeding or peripheral injection of the anorexigenic hormones leptin or CCK increased BDNF protein levels in this area (Bariohay et al., 2005). This observation suggests that BDNF in the DVC may regulate food intake. However, it remains to be determined whether BDNF in the DVC is synthesized locally or comes from other brain regions through retrograde or anterograde transport. If the BDNF protein is locally generated, it would be important to investigate in which neuronal populations refeeding and anorexigenic factors act to regulate $B d n f$ gene expression.

Mice in which $\operatorname{Trk} B$ gene expression was reduced to a quarter of the normal amount, or the $B d n f$ gene was deleted in CaMKII $\alpha$-expressing neurons, displayed markedly increased food intake on high fat diet compared to low fat diet (Xu et al., 2003; Cordeira et al., 2010). This observation indicates that BDNF is 
involved in hedonic feeding in response to palatable diet, in addition to its role in the homeostatic regulation of energy balance in response to fat stores and peripheral signals of nutrient status. This hedonic phenotype is dependent on the action of VTAderived BDNF in the NAc, since consumption of high fat diet decreased $B d n f$ mRNAs in the VTA and deletion of the $B d n f$ gene in the VTA induced hyperphagia on high fat diet but not low fat diet (Cordeira et al., 2010).

Neurons produce two forms of $B d n f$ mRNA encoding the same protein due to the presence of two alternative polyadenylation sites: short $3^{\prime}$ UTR $B d n f$ mRNA and long $3^{\prime}$ UTR $B d n f$ mRNA. One study indicates that BDNF protein regulating food intake is translated from long $3^{\prime}$ UTR $B d n f$ mRNA, likely in dendrites (Liao et al., 2012). This study used a mouse mutant with multiple SV40 polyadenylation signal sequences inserted shortly downstream of the first $B d n f$ polyadenylation site, such that the long Bdnf 3' UTR is truncated (Gorski et al., 2003; An et al., 2008). The mutant mice were found to lack dendritic $B d n f$ mRNA (An et al., 2008) and developed severe hyperphagic obesity (Liao et al., 2012). Importantly, early viral expression of long, but not short, $3^{\prime}$ UTR Bdnf mRNA in the VMH and nearby regions completely prevented these animals from developing hyperphagia and obesity (Liao et al., 2012). It remains unknown, however, in which specific neuronal populations BDNF is translated from long $3^{\prime}$ UTR $B d n f$ mRNA to regulate appetite.

\section{ACTION SITES OF BDNF TO CONTROL ENERGY HOMEOSTASIS}

Not much is known about the action sites of BDNF with regard to its role in the control of energy homeostasis. BDNF exerts its biological effects through two receptors, TrkB and $\mathrm{p} 75^{\mathrm{NTR}}$ (Reichardt, 2006). Since mutations in the gene for TrkB, but not p75 ${ }^{\mathrm{NTR}}$, lead to obesity in humans and mice (Lee et al., 1992; Xu et al., 2003; Yeo et al., 2004), BDNF should act on the TrkB receptor to mediate its effects on appetite and energy expenditure. BDNF produced in a neuron can reach TrkB-expressing neurons through four modes (DiStefano et al., 1992; von Bartheld et al., 1996; Altar et al., 1997): being released and binding to TrkB on the same neuron (autocrine) or neighboring neurons (paracrine); being anterogradely transported to the axonal terminals of the neuron and released to bind $\operatorname{TrkB}$ on targeted neurons (anterograde); and being retrogradely transported to cell bodies of innervating neurons following release and binding to TrkB on innervating axonal terminals (retrograde). Because of the complexity of BDNF action and the widespread expression of BDNF and TrkB in the brain, it is a challenge to identify TrkB-expressing neuron populations that mediate the effects of BDNF on energy homeostasis.

Pharmacological studies have suggested several putative sites where BDNF acts to control energy homeostasis. Direct injection of BDNF into either the PVH or the $\mathrm{VMH}$ of adult rats was found to decrease food intake and increase energy expenditure (Wang et al., 2007a,b,c, 2010). Delivery of BDNF into the medial NTS of the brainstem also reduced food intake and increased thermogenesis, and these effects could be blocked with a TrkB antagonist (Spaeth et al., 2012). It remains to be determined whether endogenous BDNF at these anatomical sites also has similar effects on energy homeostasis. The PVH, VMH, and NTS are complex structures and contain many distinct neuronal populations. It is important to determine on which populations of TrkB-expressing neurons BDNF acts to regulate energy homeostasis. These questions can be addressed using conditional TrkB mouse knockouts. Once the neuronal populations are identified, researchers can focus on the mechanisms by which BDNF modulates the function of these neurons.

In addition to the hypothalamus and the brainstem, the mesolimbic dopamine system may be another target for BDNF to affect food intake, especially hedonic eating. Consumption of high fat diet was found to increase TrkB mRNA in the VTA (Cordeira et al., 2010). Mice with impaired BDNF signaling exhibited much more severe hyperphagia on fat-rich diet than on low-fat diet (Xu et al., 2003; Cordeira et al., 2010). Mice lacking BDNF synthesis in CaMKII $\alpha$-expressing neurons displayed hypersensitivity of the dopamine receptor $\mathrm{D}_{1}$, such that peripheral injection of a $D_{1}$ receptor agonist normalized the hyperphagia on high-fat diet (Cordeira et al., 2010). The effect of BDNF deficiency on the dopamine receptor $\mathrm{D}_{1}$ is likely indirect, as the vast majority of TrkB-expressing neurons are striatal medium-sized spiny neurons that express the dopamine receptor $\mathrm{D}_{2}$ (Baydyuk et al., 2011b). This indirect effect may be a compensatory response to decreased evoked release of dopamine in the NAc and the dorsal striatum. As the VTA has been identified as an important source of BDNF contributing to regulation of hedonic eating (Cordeira et al., 2010), it would be interesting to determine whether BDNF acts on TrkB-expressing neurons in the VTA or the nucleus accumbens to regulate consumption of palatable food. It is critical to understand the changes in the structure and function of the neural circuitry for reward when BDNF signaling is impaired, which leads to hyperphagia on high-fat diet, since excessive intake of high fat diet is likely an important cause of the obesity pandemic in humans.

It is worth noting that one study reported that while central administration of TrkB agonists was anorexigenic in non-human primates, similar to what has been observed for rodents, peripheral administration was orexigenic, opposite to what is observed for rodents (Lin et al., 2008). Although the observation has to be reproduced, this brings into question the assumption that BDNF regulates energy balance solely through activation of central pathways. One possible peripheral BDNF target might be the vagal afferents (Fox et al., 2012).

\section{DIRECT REGULATION OF GLUCOSE HOMEOSTASIS BY BDNF}

Obesity in mice with BDNF deficiency is associated with hyperglycemia and impaired glucose tolerance (Kernie et al., 2000; Rios et al., 2001; Liao et al., 2012), and this glucose phenotype is at least in part attributable to the direct action of BDNF on glucose homeostasis. In several animal models of obesity and diabetes, including $d b / d b$ mice, diet-induced obesity mice and lethal yellow agouti mice, peripheral administration of BDNF has been shown to prevent or ameliorate the diabetic and obese phenotypes (Nakagawa et al., 2003; Yamanaka et al., 2008). In $d b / d b$ mice, BDNF could potentiate the action of insulin in peripheral tissues, reducing serum glucose in obese, diabetic $d b / d b$ mice (Ono et al., 1997). The requirement for insulin to mediate 
the hypoglycemic effect of peripheral BDNF was demonstrated in streptozotocin-induced type 1 diabetic mice, which had no reduction in blood glucose levels after BDNF treatment alone, but showed an increased hypoglycemic action of insulin when co-administered with BDNF (Nakagawa et al., 2000). Peripheral BDNF administration lead to decreased fed blood glucose levels in obese diabetic $d b / d b$ mice by affecting blood glucose control, rather than food intake. BDNF administration also normalized fasted blood glucose levels, possibly through reduced hepatomegaly (Tonra et al., 1999). Even intermittent peripheral administration of BDNF was effective at reducing blood glucose levels in obese diabetic $d b / d b$ mice, suggesting a long-lasting effect of BDNF on the control of glucose metabolism (Ono et al., 2000). The lower levels of pancreatic insulin and elevated levels of glucagon in hyperglycemic $d b / d b$ mice were restored to normal levels by BDNF treatment, with increased islet beta-cell area in BDNF-treated mice and a reversal of the decrease in pancreatic secretory granules, indicating a role for peripheral BDNF in restoring impaired pancreatic insulin production and secretion in $d b / d b$ mice (Nakagawa et al., 2000; Yamanaka et al., 2006).

CNS neurons may mediate some effects of peripheral BDNF administration on glucose homeostasis. Chronic subcutaneous BDNF administration in $d b / d b$ mice led to increased insulin receptor activation in the liver and insulin-stimulated PI3K activity in the liver, skeletal muscle and IBAT. However, no direct effect of BDNF was found on cultured hepatocytes, L6 muscle cells or 3T3-L1 adipocytes, suggesting an indirect route of action. This may possibly be through regulation of central mechanisms leading to peripheral signaling, as suggested by the observation that centrally administered BDNF also had hypoglycemic effects, and led to similar increases in liver insulin receptor activation and insulin-stimulated PI3K activity (Nakagawa et al., 2000; Tsuchida et al., 2001). Peripheral administration of BDNF increased glucose uptake and norepinephrine content in muscle and IBAT of $d b / d b$ mice, indicating the activation of sympathetic pathways to regulate glucose metabolism (Yamanaka et al., 2007). It remains unclear how peripherally administered BDNF gets into the CNS and which CNS neurons BDNF acts on to regulate glucose uptake through the sympathetic nervous system.

\section{INTERACTION OF BDNF-TrKB SIGNALING WITH OTHER ANOREXIGENIC FACTORS}

Several studies indicate that BDNF acts downstream of anorexigenic factors such as leptin and CCK to regulate food intake and body weight. Peripheral leptin administration was found to increase Bdnf mRNA levels in the VMH (Komori et al., 2006) and BDNF protein levels in the DVC (Bariohay et al., 2005). Peripheral CCK injection also increased BDNF protein levels in the DVC and hypothalamus (Bariohay et al., 2005). These effects on BDNF protein levels likely result from increased translation of $B d n f$ mRNA in dendrites, as leptin increased dendritic $B d n f$ mRNA translation in cultured hypothalamic neurons (Liao et al., 2012). In support of this argument, CCK increased BDNF protein levels in the DVC within $30 \mathrm{~min}$ (Bariohay et al., 2005), a duration that may be too short for regulation at the transcriptional level. Leptin exerts its physiological action through the long-form leptin receptor LepRb (Chua et al., 1996; Lee et al., 1996). Interestingly, BDNF-expressing neurons in the DMH and $\mathrm{VMH}$ do not express LepRb, but leptin administration was found to induce expression of c-Fos in these neurons (Liao et al., 2012). This observation indicates that leptin indirectly stimulates synthesis of $B d n f$ mRNA and BDNF protein, likely by activating BDNF-expressing neurons through a polysynaptic neural circuit.

BDNF signaling through the TrkB receptor is necessary for the anorexigenic action of leptin. Peripheral leptin injections reduced food intake in wild-type mice, but failed to do so in mice lacking long 3' UTR Bdnf mRNA (Liao et al., 2012). Leptin administration into the mNTS also reduced food intake, and co-administration of a TrkB antagonist attenuated the intakesuppressive effect of leptin (Spaeth et al., 2012). Activation of LepRb by leptin induces phosphorylation of signal transducer and activator of transcription protein 3 (STAT3) (Munzberg et al., 2003). In the DMH and VMH of mice and rats, leptin activates STAT3 and induces c-Fos expression in distinct neuronal populations (Hubschle et al., 2001; Liao et al., 2012), indicating that LepRb-expressing neurons send inputs to non-LepRb-expressing neurons and subsequently induce c-Fos expression in these cells. In mice lacking long $3^{\prime}$ UTR $B d n f$ mRNA, leptin injection activated LepRb normally in the ARC, DMH, and VMH, as indicated by phosphorylation of STAT3; however, leptin-induced c-Fos expression was impaired in the ARC and $\mathrm{VMH}$ and abolished in the DMH (Liao et al., 2012). These observations indicate that one way by which BDNF controls energy homeostasis is to regulate the formation, maintenance, and/or function of neuronal connections. When BDNF signaling is compromised, neural circuits in these hypothalamic areas are dysfunctional and fail to transmit the anorexigenic signal of leptin, leading to leptin resistance and obesity.

BDNF also interacts with the melanocortin system to regulate energy homeostasis. The initial consideration of this interaction arose from the appreciation of similar obesity phenotypes between $\operatorname{TrkB}$ mutant mice and $M c 4 r^{-/-}$knockout mice (Xu et al., 2003). Both mutants exhibit increased linear growth, more severe obesity in females than in males, and extremely increased appetite on fat-rich diet (Huszar et al., 1997; Butler et al., 2001; $\mathrm{Xu}$ et al., 2003). Furthermore, BDNF infusion into the lateral ventricle suppressed the hyperphagia and excessive weight gain observed on fat-rich diet in agouti lethal yellow mice that overexpress the agouti protein, an antagonist of melanocortin receptors (Xu et al., 2003). Additional evidence for BDNF acting downstream of the MC4R was obtained from $\operatorname{Trk} B^{F 616 A}$ mice in which the phenylalanine residue at position 616 of the $\operatorname{TrkB}$ receptor is changed to an alanine residue, which makes the TrkB kinase sensitive to inhibition by the small molecule $1 \mathrm{NaPP} 1$ (Chen et al., 2005). Systemic administration of 1NaPP1 in these mice abolished the anorexigenic effect of a selective MC4R agonist (Bariohay et al., 2009). Melanocortin agonists were found to increase Bdnf mRNA levels in the VMH (Xu et al., 2003), to increase BDNF protein levels in the DVC (Bariohay et al., 2009), and to stimulate BDNF release from hypothalamic slices (Nicholson et al., 2007). Given that neuronal activity stimulates gene expression and release of BDNF (Waterhouse and Xu, 2009), MC4R signaling may enhance TrkB activity by either directly or 
indirectly stimulating BDNF-expressing neurons. $\alpha$-MSH acts on the MC4R mainly in the PVH and the intermediolateral cell column of the thoracic spinal cord to regulate food intake and energy expenditure (Balthasar et al., 2005; Rossi et al., 2011), and thus further studies are needed to investigate the interaction between the MC4R and the BDNF-TrkB pathway in these two nuclei.

\section{SUMMARY AND PERSPECTIVE}

Strong evidence of a crucial role for BDNF in the control of energy homeostasis has been accumulated from genetic and pharmacological studies during the last decade or so. The Val66Met polymorphism in the Bdnf gene is a common allele (Shimizu et al., 2004) and has been linked to human obesity (Hotta et al., 2009; Thorleifsson et al., 2009). It is likely that BDNF acts downstream of many anorexigenic factors to control body weight. Thus, elucidation of the mechanisms by which BDNF controls appetite and energy expenditure should have important implications for

\section{REFERENCES}

Aid, T., Kazantseva, A., Piirsoo, M., Palm, K., and Timmusk, T. (2007). Mouse and rat BDNF gene structure and expression revisited. J. Neurosci. Res. 85, 525-535.

Altar, C. A., Cai, N., Bliven, T., Juhasz, M., Conner, J. M., Acheson, A. L., et al. (1997). Anterograde transport of brain-derived neurotrophic factor and its role in the brain. Nature 389, 856-860.

An, J. J., Gharami, K., Liao, G. Y., Woo, N. H., Lau, A. G., Vanevski, F., et al. (2008). Distinct role of long 3' UTR BDNF mRNA in spine morphology and synaptic plasticity in hippocampal neurons. Cell 134, 175-187.

Baj, G., Leone, E., Chao, M. V., and Tongiorgi, E. (2011). Spatial segregation of BDNF transcripts enables BDNF to differentially shape distinct dendritic compartments. Proc. Natl. Acad. Sci. U.S.A. 108, 16813-16818.

Balthasar, N., Dalgaard, L. T., Lee, C. E., Yu, J., Funahashi, H., Williams, T., et al. (2005). Divergence of melanocortin pathways in the control of food intake and energy expenditure. Cell 123, 493-505.

Barbacid, M. (1994). The Trk family of neurotrophin receptors. J. Neurobiol. 25, 1386-1403.

Bariohay, B., Lebrun, B., Moyse, E., and Jean, A. (2005). Brain-derived neurotrophic factor plays a role as an anorexigenic factor in the dorsal vagal complex. Endocrinology 146, 5612-5620.

Bariohay, B., Roux, J., Tardivel, C., Trouslard, J., Jean, A., and Lebrun, B. (2009). Brain-derived neurotrophic factor/tropomyosinrelated kinase receptor type B signaling is a downstream effector of the brainstem melanocortin system in food intake control. Endocrinology 150, 2646-2653.

Barr, V. A., Malide, D., Zarnowski, M. J., Taylor, S. I., and Cushman, S. W. (1997). Insulin stimulates both leptin secretion and production by rat white adipose tissue. Endocrinology 138, 4463-4472.

Batterham, R. L., Cowley, M. A., Small, C. J., Herzog, H., Cohen, M. A., Dakin, C. L., et al. (2002). Gut hormone PYY(3-36) physiologically inhibits food intake. Nature 418, 650-654.

Baydyuk, M., Nguyen, M. T., and Xu, B. (2011a). Chronic deprivation of TrkB signaling leads to selective late-onset nigrostriatal dopaminergic degeneration. Exp. Neurol. 228, 118-125.

Baydyuk, M., Russell, T., Liao, G. Y., Zang, K., An, J. J., Reichardt, L. F., et al. (2011b). TrkB receptor controls striatal formation by regulating the number of newborn striatal neurons. Proc. Natl. Acad. Sci. U.S.A. 108, 1669-1674.

Bibel, M., and Barde, Y. A. (2000). Neurotrophins: key regulators of cell fate and cell shape in the vertebrate nervous system. Genes Dev. 14, 2919-2937.

Boden, G., Chen, X., Kolaczynski, J. W., and Polansky, M. (1997). Effects of prolonged hyperinsulinemia on serum leptin in normal human subjects. J. Clin. Invest. 100, 1107-1113.

Bouret, S. G., Draper, S. J., and Simerly, R. B. (2004). Trophic action of leptin on hypothalamic neurons that regulate feeding. Science 304, 108-110.

Bramham, C. R., and Wells, D. G. (2007). Dendritic mRNA: transport,

human health. Recent studies indicate that synaptic plasticity in the hypothalamus plays a crucial role in its control of energy homeostasis (Pinto et al., 2004; Yang et al., 2011; Liu et al., 2012). Given its important role in synaptic plasticity, BDNF may regulate energy homeostasis by modulating synaptic plasticity in relevant areas. With the availability of more and more Cre transgenic mice and circuitry-mapping tools, it is becoming feasible to identify the neural circuits mediating the effects of BDNF on energy homeostasis. Identification of these circuits and elucidation of the mechanisms by which BDNF acts on them will greatly enhance our understanding of human obesity and hopefully bring us closer to a strategy for designing effective drug treatments for this disease.

\section{ACKNOWLEDGMENTS}

This work was supported by the grant from the US National Institutes of Health to Baoji Xu (R01 DK089237).

translation and function. Nat. Rev. Neurosci. 8, 776-789.

Butler, A. A., Marks, D. L., Fan, W. Kuhn, C. M., Bartolome, M., and Cone, R. D. (2001). Melanocortin4 receptor is required for acute homeostatic responses to increased dietary fat. Nat. Neurosci. 4, 605-611.

Cannon, B., and Nedergaard, J. (2004). Brown adipose tissue: function and physiological significance. Physiol. Rev. 84, 277-359.

Cano, G., Passerin, A. M., Schiltz, J. C. Card, J. P., Morrison, S. F., and Sved, A. F. (2003). Anatomical substrates for the central control of sympathetic outflow to interscapular adipose tissue during cold exposure. J. Comp. Neurol. 460, 303-326.

Cao, L., Choi, E. Y., Liu, X., Martin, A., Wang, C., Xu, X., et al. (2011). White to brown fat phenotypic switch induced by genetic and environmental activation of a hypothalamic-adipocyte axis. Cell Metab. 14, 324-338.

Chao, M. V. (2003). Neurotrophins and their receptors: a convergence point for many signalling pathways. Nat. Rev. Neurosci. 4, 299-309.

Chen, W. G., Chang, Q., Lin, Y., Meissner, A., West, A. E., Griffith, E. C., et al. (2003). Derepression of BDNF transcription involves calcium-dependent phosphorylation of MeCP2. Science 302, 885-889.

Chen, X., Ye, H., Kuruvilla, R., Ramanan, N., Scangos, K. W., Zhang, C., et al. (2005). A chemicalgenetic approach to studying neurotrophin signaling. Neuron 46, 13-21.

Chen, Z. Y., Jing, D., Bath, K. G., Ieraci, A., Khan, T., Siao, C. J., et al. (2006). Genetic variant BDNF (Val66Met) polymorphism alters anxiety-related behavior. Science 314, 140-143.

Chiaruttini, C., Vicario, A., Li, Z., Baj, G., Braiuca, P., Wu, Y., et al. (2009) Dendritic trafficking of BDNF mRNA is mediated by translin and blocked by the G196A (Val66Met) mutation. Proc. Natl. Acad. Sci. U.S.A. 106, 16481-16486.

Chua, S. C. Jr., Chung, W. K., Wu-Peng, X. S., Zhang, Y., Liu, S. M., Tartaglia, L., et al. (1996). Phenotypes of mouse diabetes and rat fatty due to mutations in the OB (leptin) receptor. Science 271, 994-996.

Clapham, J. C. (2012). Central control of thermogenesis. Neuropharmacology 63, 111-123.

Conner, J. M., Lauterborn, J. C., Yan, Q., Gall, C. M., and Varon, S. (1997). Distribution of brainderived neurotrophic factor (BDNF) protein and mRNA in the normal adult rat CNS: evidence for anterograde axonal transport. J. Neurosci. 17, 2295-2313.

Coppari, R., Ichinose, M., Lee, C. E., Pullen, A. E., Kenny, C. D., McGovern, R. A., et al. (2005). The hypothalamic arcuate nucleus: a key site for mediating leptin's effects on glucose homeostasis and locomotor activity. Cell Metab. 1, 63-72.

Coppola, V., and Tessarollo, L. (2004). Control of hyperphagia prevents obesity in BDNF heterozygous mice. Neuroreport 15, 2665-2668.

Cordeira, J. W., Frank, L., Sena-Esteves, M., Pothos, E. N., and Rios, M. (2010). Brain-derived neurotrophic factor regulates hedonic feeding by acting on the mesolimbic dopamine system. J. Neurosci. 30, 2533-2541. 
Cota, D., Proulx, K., Smith, K. A., Kozma, S. C., Thomas, G., Woods, S. C., et al. (2006). Hypothalamic mTOR signaling regulates food intake. Science 312, 927-930.

Cowley, M. A., Smart, J. L., Rubinstein, M., Cerdan, M. G., Diano, S., Horvath, T. L., et al. (2001). Leptin activates anorexigenic POMC neurons through a neural network in the arcuate nucleus. Nature 411, 480-484.

Dhillon, H., Zigman, J. M., Ye, C., Lee, C. E., McGovern, R. A., Tang, V., et al. (2006). Leptin directly activates $\mathrm{SF} 1$ neurons in the $\mathrm{VMH}$, and this action by leptin is required for normal body-weight homeostasis. Neuron 49, 191-203.

Diniz, B. S., and Teixeira, A. L. (2011). Brain-derived neurotrophic factor and Alzheimer's disease: physiopathology and beyond. Neuromolecular Med. 13, 217-222.

DiStefano, P. S., Friedman, B., Radziejewski, C., Alexander, C., Boland, P., Schick, C. M., et al. (1992). The neurotrophins BDNF, NT-3, and NGF display distinct patterns of retrograde axonal transport in peripheral and central neurons. Neuron 8, 983-993.

Dockray, G. J. (2012). Cholecystokinin. Curr. Opin. Endocrinol. Diabetes Obes. 19, 8-12.

Egan, M. F., Kojima, M., Callicott, J. H., Goldberg, T. E., Kolachana, B. S., Bertolino, A., et al. (2003). The BDNF val66met polymorphism affects activity-dependent secretion of BDNF and human memory and hippocampal function. Cell 112, 257-269.

Ellacott, K. L., and Cone, R. D. (2006). The role of the central melanocortin system in the regulation of food intake and energy homeostasis: lessons from mouse models. Philos. Trans. R. Soc. Lond. B Biol. Sci. 361, 1265-1274.

Elmquist, J. K., Maratos-Flier, E., Saper, C. B., and Flier, J. S. (1998). Unraveling the central nervous system pathways underlying responses to leptin. Nat. Neurosci. 1, 445-450.

Fischbach, B. V., Trout, K. L., Lewis, J., Luis, C. A., and Sika, M. (2005). WAGR syndrome: a clinical review of 54 cases. Pediatrics 116, 984-988.

Flier, J. S. (2004). Obesity wars: molecular progress confronts an expanding epidemic. Cell 116, 337-350.

Fox, E. A., Biddinger, J. E., Jones, K. R., McAdams, J., and Worman, A. (2012). Mechanism of hyperphagia contributing to obesity in brain-derived neurotrophic factor knockout mice. Neuroscience 229, 176-199.
Gorski, J. A., Zeiler, S. R., Tamowski, S., and Jones, K. R. (2003). Brainderived neurotrophic factor is required for the maintenance of cortical dendrites. J. Neurosci. 23, 6856-6865.

Gratacos, M., Gonzalez, J. R., Mercader, J. M., de Cid, R., Urretavizcaya, M., and Estivill, X. (2007). Brainderived neurotrophic factor Val66Met and psychiatric disorders: meta-analysis of case-control studies confirm association to substance-related disorders, eating disorders, and schizophrenia. Biol. Psychiatry 61, 911-922.

Gray, J., Yeo, G. S., Cox, J. J., Morton, J., Adlam, A. L., Keogh, J. M., et al. (2006). Hyperphagia, severe obesity, impaired cognitive function, and hyperactivity associated with functional loss of one copy of the brain-derived neurotrophic factor (BDNF) gene. Diabetes 55, 3366-3371.

Halban, P. A., and Irminger, J. C. (1994). Sorting and processing of secretory proteins. Biochem. J. 299(Pt 1), 1-18.

Hamann, A., and Matthaei, S. (1996). Regulation of energy balance by leptin. Exp. Clin. Endocrinol. Diabetes 104, 293-300.

Han, J. C., Liu, Q. R., Jones, M., Levinn, R. L., Menzie, C. M., JeffersonGeorge, K. S., et al. (2008). Brainderived neurotrophic factor and obesity in the WAGR syndrome. $N$. Engl. J. Med. 359, 918-927.

He, W., Lam, T. K., Obici, S., and Rossetti, L. (2006). Molecular disruption of hypothalamic nutrient sensing induces obesity. Nat Neurosci. 9, 227-233.

Hofer, M., Pagliusi, S. R., Hohn, A., Leibrock, J., and Barde, Y A. (1990). Regional distribution of brain-derived neurotrophic factor mRNA in the adult mouse brain. EMBO J. 9, 2459-2464.

Hotta, K., Nakamura, M., Nakamura, T., Matsuo, T., Nakata, Y., Kamohara, S., et al. (2009). Association between obesity and polymorphisms in SEC16B, TMEM18, GNPDA2, BDNF, FAIM2 and MC4R in a Japanese population. J. Hum. Genet. 54, 727-731.

Huang, E. J., and Reichardt, L. F. (2001). Neurotrophins: roles in neuronal development and function. Annu. Rev. Neurosci. 24 677-736.

Hubschle, T., Thom, E., Watson, A. Roth, J., Klaus, S., and Meyerhof, W. (2001). Leptin-induced nuclear translocation of STAT3 immunoreactivity in hypothalamic nuclei involved in body weight regulation. J. Neurosci. 21, 2413-2424.

Huszar, D., Lynch, C. A., FairchildHuntress, V., Dunmore, J. H., Fang, Q., Berkemeier, L. R., et al. (1997). Targeted disruption of the melanocortin-4 receptor results in obesity in mice. Cell 88, 131-141.

Katoh-Semba, R., Takeuchi, I. K., Semba, R., and Kato, K. (1997). Distribution of brain-derived neurotrophic factor in rats and its changes with development in the brain. J. Neurochem. 69, 34-42.

Kernie, S. G., Liebl, D. J., and Parada L. F. (2000). BDNF regulates eating behavior and locomotor activity in mice. EMBO J. 19, 1290-1300.

Kojima, M., Hosoda, H., Date, Y., Nakazato, M., Matsuo, H., and Kangawa, K. (1999). Ghrelin is a growth-hormone-releasing acylated peptide from stomach. Nature 402 , 656-660.

Komori, T., Morikawa, Y., Nanjo, K., and Senba, E. (2006). Induction of brain-derived neurotrophic factor by leptin in the ventromedial hypothalamus. Neuroscience 139, 1107-1115.

Lapchak, P. A., and Hefti, F. (1992). BDNF and NGF treatment in lesioned rats: effects on cholinergic function and weight gain. Neuroreport 3, 405-408.

Lee, G. H., Proenca, R., Montez, J. M., Carroll, K. M., Darvishzadeh, J. G. Lee, J. I., et al. (1996). Abnormal splicing of the leptin receptor in diabetic mice. Nature 379, 632-635.

Lee, K. F., Li, E., Huber, L. J., Landis, S. C., Sharpe, A. H., Chao, M. V. et al. (1992). Targeted mutation of the gene encoding the low affinity NGF receptor p75 leads to deficits in the peripheral sensory nervous system. Cell 69, 737-749.

Lessmann, V., Gottmann, K. and Malcangio, M. (2003). Neurotrophin secretion: current facts and future prospects. Prog. Neurobiol. 69, 341-374.

Liao, G. Y., An, J. J., Gharami, K. Waterhouse, E. G., Vanevski, F., Jones, K. R., et al. (2012). Dendritically targeted Bdnf mRNA is essential for energy balance and response to leptin. Nat. Med. 18, 564-571.

Lin, C. R., Kapiloff, M. S., Durgerian, S., Tatemoto, K., Russo, A. F., Hanson, P., et al. (1987). Molecular cloning of a brain-specific calcium/calmodulin-dependent protein kinase. Proc. Natl. Acad. Sci. U.S.A. 84, 5962-5966.

Lin, J. C., Tsao, D., Barras, P., Bastarrachea, R. A., Boyd, B. Chou, J., et al. (2008). Appetite enhancement and weight gain by peripheral administration of TrkB agonists in non-human primates. PLoS ONE 3:e1900. doi 10.1371/journal.pone.0001900

Liu, T., Kong, D., Shah, B. P., Ye, C., Koda, S., Saunders, A., et al. (2012). Fasting activation of AgRP neurons requires NMDA receptors and involves spinogenesis and increased excitatory tone. Neuron $73,511-522$.

Loftus, T. M., Jaworsky, D. E., Frehywot, G. L., Townsend, C. A., Ronnett, G. V., Lane, M. D., et al. (2000). Reduced food intake and body weight in mice treated with fatty acid synthase inhibitors. Science 288, 2379-2381.

Lyons, W. E., Mamounas, L. A. Ricaurte, G. A., Coppola, V., Reid, S. W., Bora, S. H., et al. (1999). Brain-derived neurotrophic factor-deficient mice develop aggressiveness and hyperphagia in conjunction with brain serotonergic abnormalities. Proc. Natl. Acad. Sci. U.S.A. 96, 15239-15244.

Masana, Y., Wanaka, A., Kato, H. Asai, T., and Tohyama, M. (1993). Localization of trkB mRNA in postnatal brain development. J. Neurosci. Res. 35, 468-479.

Morton, G. J., Cummings, D. E., Baskin, D. G., Barsh, G. S., and Schwartz, M. W. (2006). Central nervous system control of food intake and body weight. Nature 443 , 289-295.

Mowla, S. J., Pareek, S., Farhadi, H. F. Petrecca, K., Fawcett, J. P., Seidah, N. G., et al. (1999). Differential sorting of nerve growth factor and brainderived neurotrophic factor in hippocampal neurons. J. Neurosci. 19, 2069-2080.

Munzberg, H., Huo, L., Nillni, E. A. Hollenberg, A. N., and Bjorbaek, C. (2003). Role of signal transducer and activator of transcription 3 in regulation of hypothalamic proopiomelanocortin gene expression by leptin. Endocrinology 144, 2121-2131.

Nakagawa, T., Ogawa, Y., Ebihara, K., Yamanaka, M., Tsuchida, A., Taiji, M., et al. (2003). Anti-obesity and anti-diabetic effects of brainderived neurotrophic factor in rodent models of leptin resistance. Int. J. Obes. Relat. Metab. Disord. 27, 557-565.

Nakagawa, T., Tsuchida, A., Itakura, Y., Nonomura, T., Ono, M., Hirota, F., et al. (2000). Brain-derived neurotrophic factor regulates glucose metabolism by modulating energy balance in diabetic mice. Diabetes 49, 436-444. 
Nakazato, M., Murakami, N., Date, Y., Kojima, M., Matsuo, H., Kangawa, K., et al. (2001). A role for ghrelin in the central regulation of feeding. Nature 409, 194-198.

Nicholson, J. R., Peter, J. C., Lecourt, A. C., Barde, Y. A., and Hofbauer, K. G. (2007). Melanocortin-4 receptor activation stimulates hypothalamic brain-derived neurotrophic factor release to regulate food intake, body temperature and cardiovascular function. J. Neuroendocrinol. 19, 974-982.

Nonomura, T., Tsuchida, A., OnoKishino, M., Nakagawa, T., Taiji, M., and Noguchi, H. (2001). Brainderived neurotrophic factor regulates energy expenditure through the central nervous system in obese diabetic mice. Int. J. Exp. Diabetes Res. 2, 201-209.

Oldfield, B. J., Giles, M. E., Watson, A., Anderson, C., Colvill, L. M., and McKinley, M. J. (2002). The neurochemical characterisation of hypothalamic pathways projecting polysynaptically to brown adipose tissue in the rat. Neuroscience 110, 515-526.

Ollmann, M. M., Wilson, B. D., Yang, Y. K., Kerns, J. A., Chen, Y., Gantz, I., et al. (1997). Antagonism of central melanocortin receptors in vitro and in vivo by agouti-related protein. Science 278, 135-138.

Ono, M., Ichihara, J., Nonomura, T., Itakura, Y., Taiji, M., Nakayama, C., et al. (1997). Brain-derived neurotrophic factor reduces blood glucose level in obese diabetic mice but not in normal mice. Biochem. Biophys. Res. Commun. 238, 633-637.

Ono, M., Itakura, Y., Nonomura, T., Nakagawa, T., Nakayama, C., Taiji, M., et al. (2000). Intermittent administration of brain-derived neurotrophic factor ameliorates glucose metabolism in obese diabetic mice. Metabolism 49, 129-133.

Pang, P. T., Teng, H. K., Zaitsev, E., Woo, N. T., Sakata, K., Zhen, S., et al. (2004). Cleavage of proBDNF by $\mathrm{tPA} /$ plasmin is essential for longterm hippocampal plasticity. Science 306, 487-491.

Parker, J. A., and Bloom, S. R. (2012). Hypothalamic neuropeptides and the regulation of appetite. Neuropharmacology 63, 18-30.

Patapoutian, A., and Reichardt, L. F. (2001). Trk receptors: mediators of neurotrophin action. Curr. Opin. Neurobiol. 11, 272-280.

Pelleymounter, M. A., Cullen, M. J., and Wellman, C. L. (1995). Characteristics of BDNF-induced weight loss. Exp. Neurol. 131, 229-238.

Pinto, S., Roseberry, A. G., Liu, H., Diano, S., Shanabrough, M., Cai, X., et al. (2004). Rapid rewiring of arcuate nucleus feeding circuits by leptin. Science 304, 110-115.

Pocai, A., Lam, T. K., Obici, S., Gutierrez-Juarez, R., Muse, E. D., Arduini, A., et al. (2006). Restoration of hypothalamic lipid sensing normalizes energy and glucose homeostasis in overfed rats. J. Clin. Invest. 116, 1081-1091.

Reichardt, L. F. (2006). Neurotrophinregulated signalling pathways. Philos. Trans. R. Soc. Lond. B Biol. Sci. 361, 1545-1564.

Ribases, M., Gratacos, M., FernandezAranda, F., Bellodi, L., Boni, C., Anderluh, M., et al. (2004). Association of BDNF with anorexia, bulimia and age of onset of weight loss in six European populations. Hum. Mol. Genet. 13, 1205-1212.

Rios, M., Fan, G., Fekete, C., Kelly, J., Bates, B., Kuehn, R., et al. (2001). Conditional deletion of brainderived neurotrophic factor in the postnatal brain leads to obesity and hyperactivity. Mol. Endocrinol. 15, 1748-1757.

Rossi, J., Balthasar, N., Olson, D., Scott, M., Berglund, E., Lee, C. E., et al. (2011). Melanocortin-4 receptors expressed by cholinergic neurons regulate energy balance and glucose homeostasis. Cell Metab. 13, 195-204.

Saladin, R., De Vos, P., Guerre-Millo, M., Leturque, A., Girard, J., Staels, B., et al. (1995). Transient increase in obese gene expression after food intake or insulin administration. Nature 377, 527-529.

Satomura, E., Baba, H., Nakano, Y., Maeshima, H., Suzuki, T., and Arai, H. (2011). Correlations between brain-derived neurotrophic factor and clinical symptoms in medicated patients with major depression. J. Affect. Disord. 135, 332-335.

Shimizu, E., Hashimoto, K., and Iyo, M. (2004). Ethnic difference of the BDNF 196G/A (val66met) polymorphism frequencies: the possibility to explain ethnic mental traits. Am. J. Med. Genet. B Neuropsychiatr. Genet. 126B, 122-123.

Spaeth, A. M., Kanoski, S. E., Hayes, M. R., and Grill, H. J. (2012). TrkB receptor signaling in the nucleus tractus solitarius mediates the food intake-suppressive effects of hindbrain BDNF and leptin. Am. J. Physiol. Endocrinol. Metab. 302, E1252-E1260.

Stehling, O., Doring, H., Ertl, J., Preibisch, G., and Schmidt, I.
(1996). Leptin reduces juvenile fat stores by altering the circadian cycle of energy expenditure. Am. J. Physiol. 271, R1770-R1774.

Sternson, S. M., Shepherd, G. M., and Friedman, J. M. (2005). Topographic mapping of VMH $\rightarrow$ arcuate nucleus microcircuits and their reorganization by fasting. Nat. Neurosci. 8, 1356-1363.

Tang-Christensen, M., Larsen, P. J., Goke, R., Fink-Jensen, A., Jessop, D. S., Moller, M., et al. (1996) Central administration of GLP-1(7-36) amide inhibits food and water intake in rats. Am. J. Physiol. 271, R848-R856.

Tao, X., Finkbeiner, S., Arnold, D. B., Shaywitz, A. J., and Greenberg, M. E. (1998). $\mathrm{Ca}^{2+}$ influx regulates BDNF transcription by a CREB family transcription factordependent mechanism. Neuron 20 709-726.

Teixeira, A. L., Barbosa, I. G., Diniz, B. S., and Kummer, A. (2010) Circulating levels of brain-derived neurotrophic factor: correlation with mood, cognition and motor function. Biomark. Med. 4, 871-887.

Teng, H. K., Teng, K. K., Lee, R., Wright, S., Tevar, S., Almeida, R. D., et al. (2005). ProBDNF induces neuronal apoptosis via activation of a receptor complex of p75NTR and sortilin. J. Neurosci. 25, 5455-5463.

Thorleifsson, G., Walters, G. B., Gudbjartsson, D. F., Steinthorsdottir, V., Sulem, P., Helgadottir, A., et al. (2009). Genome-wide association yields new sequence variants at seven loci that associate with measures of obesity. Nat. Genet. 41, 18-24.

Timmusk, T., Palm, K., Metsis, M., Reintam, T., Paalme, V., Saarma, M., et al. (1993). Multiple promoters direct tissue-specific expression of the rat BDNF gene. Neuron 10, 475-489.

Tonra, J. R., Ono, M., Liu, X., Garcia, K., Jackson, C., Yancopoulos, G. D. et al. (1999). Brain-derived neurotrophic factor improves blood glucose control and alleviates fasting hyperglycemia in C57BLKSLepr $(\mathrm{db}) /$ lepr $(\mathrm{db})$ mice. Diabetes $48,588-594$.

Tran, P. V., Akana, S. F., Malkovska, I., Dallman, M. F., Parada, L. F., and Ingraham, H. A. (2006) Diminished hypothalamic bdnf expression and impaired VMH function are associated with reduced SF-1 gene dosage. J. Comp. Neurol. 498, 637-648.

Tran, P. V., Lee, M. B., Marin, O. $\mathrm{Xu}, \mathrm{B}$., Jones, K. R., Reichardt, L. F., et al. (2003). Requirement of the orphan nuclear receptor SF-1 in terminal differentiation of ventromedial hypothalamic neurons. Mol. Cell. Neurosci. 22, 441-453.

Tsien, J. Z., Chen, D. F., Gerber, D., Tom, C., Mercer, E. H., Anderson, D. J., et al. (1996). Subregion- and cell type-restricted gene knockout in mouse brain. Cell 87, 1317-1326.

Tsuchida, A., Nakagawa, T., Itakura, Y., Ichihara, J., Ogawa, W., Kasuga, M., et al. (2001). The effects of brain-derived neurotrophic factor on insulin signal transduction in the liver of diabetic mice. Diabetologia $44,555-566$.

Turton, M. D., O'Shea, D., Gunn, I., Beak, S. A., Edwards, C. M., Meeran, K., et al. (1996). A role for glucagonlike peptide-1 in the central regulation of feeding. Nature 379, 69-72.

Unger, T. J., Calderon, G. A., Bradley, L. C., Sena-Esteves, M., and Rios, M. (2007). Selective deletion of Bdnf in the ventromedial and dorsomedial hypothalamus of adult mice results in hyperphagic behavior and obesity. J. Neurosci. 27, 14265-14274.

von Bartheld, C. S., Byers, M. R., Williams, R., and Bothwell, M. (1996). Anterograde transport of neurotrophins and axodendritic transfer in the developing visual system. Nature 379, 830-833.

Wang, C., Bomberg, E., Billington, C., Levine, A., and Kotz, C. M. (2007a). Brain-derived neurotrophic factor in the hypothalamic paraventricular nucleus reduces energy intake. Am. J. Physiol. Regul. Integr. Comp. Physiol. 293, R1003-R1012.

Wang, C., Bomberg, E., Billington, C. Levine, A., and Kotz, C. M. (2007b). Brain-derived neurotrophic factor in the hypothalamic paraventricular nucleus increases energy expenditure by elevating metabolic rate. Am. J. Physiol. Regul. Integr. Comp. Physiol. 293, R992-R1002.

Wang, C., Bomberg, E., Levine, A., Billington, C., and Kotz, C. M. (2007c). Brain-derived neurotrophic factor in the ventromedial nucleus of the hypothalamus reduces energy intake. Am. J. Physiol. Regul. Integr. Comp. Physiol. 293, R1037-R1045.

Wang, C., Bomberg, E., Billington, C. J., Levine, A. S., and Kotz, C. M. (2010). Brain-derived neurotrophic factor (BDNF) in the hypothalamic ventromedial nucleus increases energy expenditure. Brain Res. 1336, 66-77.

Waterhouse, E. G., and Xu, B. (2009). New insights into the role of brain-derived neurotrophic factor in synaptic plasticity. Mol. Cell. Neurosci. 42, 81-89. 
Williams, K. W., Scott, M. M., and Elmquist, J. K. (2011). Modulation of the central melanocortin system by leptin, insulin, and serotonin: co-ordinated actions in a dispersed neuronal network. Eur. J. Pharmacol. 660, 2-12.

Woo, N. H., Teng, H. K., Siao, C. J., Chiaruttini, C., Pang, P. T., Milner, T. A., et al. (2005). Activation of p75NTR by proBDNF facilitates hippocampal long-term depression. Nat. Neurosci. 8, 1069-1077.

Woods, S. C., Lotter, E. C., McKay, L. D., and Porte, D. Jr. (1979). Chronic intracerebroventricular infusion of insulin reduces food intake and body weight of baboons. Nature 282, 503-505.

$\mathrm{Xu}$, B., Gottschalk, W., Chow, A., Wilson, R. I., Schnell, E., Zang, K., et al. (2000a). The role of brainderived neurotrophic factor receptors in the mature hippocampus: modulation of long-term potentiation through a presynaptic mechanism involving TrkB. J. Neurosci. 20, 6888-6897.

Xu, B., Zang, K., Ruff, N. L., Zhang, Y. A., McConnell, S. K., Stryker, M. P., et al. (2000b). Cortical degeneration in the absence of neurotrophin signaling: dendritic retraction and neuronal loss after removal of the receptor TrkB. Neuron 26, 233-245.

Xu, B., Goulding, E. H., Zang, K., Cepoi, D., Cone, R. D., Jones, K. R., et al. (2003). Brain-derived neurotrophic factor regulates energy balance downstream of melanocortin-4 receptor. Nat. Neurosci. 6, 736-742.

Yamanaka, M., Itakura, Y., Inoue, T., Tsuchida, A., Nakagawa, T., Noguchi, H., et al. (2006). Protective effect of brain-derived neurotrophic factor on pancreatic islets in obese diabetic mice. Metabolism 55, 1286-1292.

Yamanaka, M., Itakura, Y., Tsuchida, A., Nakagawa, T., and Taiji, M. (2008). Brain-derived neurotrophic factor (BDNF) prevents the development of diabetes in prediabetic mice. Biomed. Res. 29, 147-153.

Yamanaka, M., Tsuchida, A., Nakagawa, T., Nonomura, T., Ono-Kishino, M., Sugaru, E., et al. (2007). Brain-derived neurotrophic factor enhances glucose utilization in peripheral tissues of diabetic mice. Diabetes. Obes. Metab. 9, 59-64.

Yan, Q., Radeke, M. J., Matheson, C. R., Talvenheimo, J., Welcher, A.
A., and Feinstein, S. C. (1997a). Immunocytochemical localization of TrkB in the central nervous system of the adult rat. J. Comp. Neurol. 378, 135-157.

Yan, Q., Rosenfeld, R. D., Matheson, C. R., Hawkins, N., Lopez, O, T., Bennett, L., et al. (1997b). Expression of brain-derived neurotrophic factor protein in the adult rat central nervous system. Neuroscience 78, 431-448.

Yang, Y., Atasoy, D., Su, H. H., and Sternson, S. M. (2011). Hunger states switch a flip-flop memory circuit via a synaptic AMPKdependent positive feedback loop. Cell 146, 992-1003.

Yang, J., Siao, C. J., Nagappan, G., Marinic, T., Jing, D., McGrath, K., et al. (2009). Neuronal release of proBDNF. Nat. Neurosci. 12, 113-115.

Yeo, G. S., Connie Hung, C. C., Rochford, J., Keogh, J., Gray, J., Sivaramakrishnan, S., et al. (2004). A de novo mutation affecting human TrkB associated with severe obesity and developmental delay. Nat. Neurosci. 7, 1187-1189.

Zhang, Y., Proenca, R., Maffei, M. Barone, M., Leopold, L., and
Friedman, J. M. (1994). Positional cloning of the mouse obese gene and its human homologue. Nature $372,425-432$.

Conflict of Interest Statement: The authors declare that the research was conducted in the absence of any commercial or financial relationships that could be construed as a potential conflict of interest.

Received: 30 December 2012; accepted: 03 March 2013; published online: 21 March 2013.

Citation: Vanevski F and Xu B (2013) Molecular and neural bases underlying roles of BDNF in the control of body weight. Front. Neurosci. 7:37. doi: 10.3389/fnins.2013.00037

This article was submitted to Frontiers in Neuroendocrine Science, a specialty of Frontiers in Neuroscience.

Copyright (c) 2013 Vanevski and Xu. This is an open-access article distributed under the terms of the Creative Commons Attribution License, which permits use, distribution and reproduction in other forums, provided the original authors and source are credited and subject to any copyright notices concerning any third-party graphics etc. 